\title{
Residential particulate matter and distance to roadways in relation to mammographic density: results from the Nurses' Health Studies
}

Natalie C. DuPre ${ }^{1,2^{*}}$, Jaime E. Hart ${ }^{2,3}$, Kimberly A. Bertrand ${ }^{4}$, Peter Kraft ${ }^{1}$, Francine Laden ${ }^{1,2,3+}$ and Rulla M. Tamimi ${ }^{1,2+}$

\begin{abstract}
Background: High mammographic density is a strong, well-established breast cancer risk factor. Three studies conducted in various smaller geographic settings reported inconsistent findings between air pollution and mammographic density. We assessed whether particulate matter (PM) exposures ( $\mathrm{PM}_{2.5}, \mathrm{PM}_{2.5-10}$, and $\left.\mathrm{PM}_{10}\right)$ and distance to roadways were associated with mammographic density among women residing across the United States.

Methods: The Nurses' Health Studies are prospective cohorts for whom a subset has screening mammograms from the 1990s (interquartile range 1990-1999). PM was estimated using spatio-temporal models linked to residential addresses. Among 3258 women (average age at mammogram 52.7 years), we performed multivariable linear regression to assess associations between square-root-transformed mammographic density and PM within 1 and 3 years before the mammogram. For linear regression estimates of PM in relation to untransformed mammographic density outcomes, bootstrapped robust standard errors are used to calculate $95 \%$ confidence intervals (Cls). Analyses were stratified by menopausal status and region of residence.

Results: Recent PM and distance to roadways were not associated with mammographic density in premenopausal women $\left(\mathrm{PM}_{2.5}\right.$ within 3 years before mammogram $\beta=0.05,95 \% \mathrm{Cl}-0.16,0.27 ; \mathrm{PM}_{2.5-10} \beta=0,95 \%, \mathrm{Cl}-0.15,0.16 ; \mathrm{PM}_{10}$ $\beta=0.02,95 \% \mathrm{Cl}-0.10,0.13)$ and postmenopausal women $\left(\mathrm{PM}_{2.5}\right.$ within 3 years before mammogram $\beta=-0.05,95 \% \mathrm{Cl}$ $\left.-0.27,0.17 ; \mathrm{PM}_{2.5-10} \beta=-0.01,95 \% \mathrm{Cl}-0.16,0.14 ; \mathrm{PM}_{10} \beta=-0.02,95 \% \mathrm{Cl}-0.13,0.09\right)$. Largely null associations were observed within regions. Suggestive associations were observed among postmenopausal women in the Northeast $(n$ = 745), where a $10-\mu \mathrm{g} / \mathrm{m}^{3}$ increase in $\mathrm{PM}_{2.5}$ within 3 years before the mammogram was associated with 3.4 percentage points higher percent mammographic density $(95 \% \mathrm{Cl}-0.5,7.3)$.

Conclusions: These findings do not support that recent PM or roadway exposures influence mammographic density. Although PM was largely not associated with mammographic density, we cannot rule out the role of PM during earlier exposure time windows and possible associations among northeastern postmenopausal women.
\end{abstract}

Keywords: Air pollution, Particulate matter, Mammographic density, Epidemiology

\footnotetext{
* Correspondence: ncd121@mail.harvard.edu

${ }^{\dagger}$ Equal contributors

'Department of Epidemiology, Harvard T.H. Chan School of Public Health,

Boston, MA, USA

${ }^{2}$ Channing Division of Network Medicine, Department of Medicine, Brigham

and Women's Hospital and Harvard Medical School, Boston, MA, USA

Full list of author information is available at the end of the article
} 


\section{Background}

In 2013, $66.8 \%$ of women in the United States aged $\geq 40$ years had undergone a mammogram within the previous 2 years [1]. Mammograms not only aid in breast tumor detection but also provide a radiographic image of the breast that distinguishes fat and fibroglandular tissue based on their differences in X-ray absorption. The fat tissue in the breast is radiolucent and appears dark on the mammogram, while the dense stromal and epithelial tissue is radiopaque and appears bright. The proportion of dense tissue area compared to the total breast tissue area yields a measure of percent breast density, which is an established breast cancer risk factor. In a meta-analysis, compared to women with less than $5 \%$ dense tissue on a mammogram, women with $50-74 \%$ dense tissue had a 3.0-fold increased risk of developing breast cancer and women with $\geq 75 \%$ dense tissue had a 4.6-fold increased risk [2]. Percent mammographic density was reported to be an intermediate marker of breast cancer risk for certain exposures, such as early life body size and hormonal therapy use, although not all breast cancer risk factors are mediated by mammographic density [3]. Therefore, identifying predictors of breast density variation may be important for breast cancer risk reduction and is becoming increasingly relevant in the United States as more than half of the states mandate that physicians notify women who have dense breasts. While many studies of breast density highlight the relevance of age, hormonal, and reproductive factors [4], limited research investigates the role of air pollutants that can bind to estrogen receptors to induce hormonal changes via endocrine disruption $[5,6]$.

The World Health Organization's International Agency for Research on Cancer classified ambient air pollution and particulate matter (PM) as Group 1 human carcinogens largely based on results from lung cancer studies [7]. However, studies of air pollution metrics and risk of breast cancer have produced inconsistent results [8-16] and have been largely null for recent PM exposures in cohort studies [17-19], but this does not rule out whether PM in early time windows of exposure influences disease incidence or whether PM influences earlier changes in the breast. In 2012, the Institute of Medicine issued a report calling on breast cancer research to address early mechanisms of breast carcinogenesis as well as the influence of environmental exposures and pollutants across the life course [20]; studying the associations of pollutants and mammographic density variation can provide insight into early breast tissue variation that may translate to breast cancer risk reduction strategies. To date, three studies conducted in smaller geographic settings within Europe and the United States assessed associations between air pollution metrics and mammographic density measures but reported inconsistent findings [21-23], likely due to differences and limitations in PM measurement methods and the use of categorical measures of mammographic density.
Given the large geographical scope of the nationwide USbased Nurses' Health Study (NHS) and NHSII cohorts and the ability to control for well-established breast cancer risk factors and predictors of mammographic density, we investigated associations between PM exposures at one's residential address and distance to roadways in relation to a continuous measure of mammographic density in women without breast cancer. We assessed the associations separately for premenopausal and postmenopausal women and within regions of the United States.

\section{Methods \\ Study population}

The NHS cohort was established in 1976, enrolling 121,700 married, female US nurses between the ages of 30 and 55 years who resided in 11 states at entry (California, Connecticut, Florida, Massachusetts, Maryland, Michigan, New Jersey, New York, Ohio, Pennsylvania, and Texas) [24]. The NHSII cohort was established in 1989, enrolling 116,430 female US nurses between the ages of 25 and 42 years residing in 14 states (California, Connecticut, Indiana, Iowa, Kentucky, Massachusetts, Michigan, Missouri, New York, North Carolina, Ohio, Pennsylvania, South Carolina, and Texas). Briefly, participants in both cohorts completed baseline and subsequent biennial questionnaires on medical history and covariate data (e.g., anthropometrics, reproductive history, and lifestyle factors) that were mailed to their residential addresses. Participants reported breast cancer diagnoses on biennial questionnaires and the diagnoses were confirmed by review of medical records. In 1989-1990 and 1996-1999 a subset of participants from the NHS and the NHSII, respectively, provided blood samples, and breast cancer case-control studies nested within the NHS (cases $n=5371$, controls $n=7469$ ) and the NHSII (cases $n=2750$, controls $n=5500$ ) were established to evaluate blood-based biomarkers of risk. Around the time of blood draw, the majority of the NHS (80.1\%) and NHSII (89.2\%) participants reported having a mammogram in the last 2 years on the 1990 and 1999 questionnaires, respectively. Film mammograms were collected from women who were participants in the nested breast cancer case-control studies and who also reported mammography around the time of blood collection. We successfully obtained mammograms from approximately $80 \%$ of the eligible participants from the NHS (cases $n=1304$, controls $n=2362$ ) and the NHSII (cases $n=758$, controls $n=1833)[25,26]$. These mammograms were primarily conducted in the early 1990s for the NHS (interquartile range (IQR) 1990-1994) and in the late 1990s for the NHSII (IQR 1997-2000). For this study, we used only mammograms from the controls that were reported as screening mammograms; mammograms for diagnostic purposes and those from breast cancer cases were excluded. Among the controls, women with and without collected mammograms were similar with regards to breast cancer 
risk factors such as age, body mass index, parity, and family history of breast cancer $[25,26]$.

\section{Outcomes: mammographic density measures}

Film mammograms of the cranio-caudal views of each breast were digitized with a Lumysis 85 laser film scanner for all NHS mammograms and for the first two batches of NHSII mammograms, and with a VIDAR CAD PRO Advantage scanner (VIDAR Systems Corporation, Herndon, VA, USA) for the third batch of NHSII mammograms. The correlation between percent density measures from the two scanners was 0.88 [27]. Trained observers were blinded to exposure status and used a computer-assisted thresholding method (Cumulus software) to measure mammographic density. Breast density measurements were averaged across both breasts. Replicate mammograms from each batch of density readings exhibited high within-person intraclass correlation coefficients $\geq 0.90$ [28]. Despite these high within-person intraclass correlation coefficients, betweenbatch variability was present in the NHSII. Batch adjustment methods were applied to the second and third NHSII batch measurements to reflect the density measurements had they been evaluated in the first batch $[26,29]$. The primary outcome of interest was percent mammographic density (i.e., the dense area divided by the total breast area), and secondary outcomes of interest included absolute dense area $\left(\mathrm{cm}^{2}\right)$ and absolute nondense area $\left(\mathrm{cm}^{2}\right)$.

\section{Exposures: particulate matter and proximity to roadways}

Residential addresses were updated biennially in both the NHS and the NHSII as part of the questionnaire mailing process. By the mid-1990s, participants resided in all 50 states [30]. Study participants' residential addresses were geocoded and linked to predicted estimates of PM and to proximity to various-sized roadways over the course of the study.

i. Particulate matter

In the current study, the primary exposures of interest were PM levels 1 year before the year of the mammogram and the cumulative average PM for up to 3 years prior to the mammogram year. Particulate matter is classified into three size fractions, including fine particles less than $2.5 \mu \mathrm{m}$ in aerodynamic diameter $\left(\mathrm{PM}_{2.5}\right)$, thoracic particles less than $10 \mu \mathrm{m}\left(\mathrm{PM}_{10}\right)$, and coarse particles between 2.5 and $10 \mu \mathrm{m}\left(\mathrm{PM}_{2.5-10}\right)$. Particulate matter comes from various sources and the varying contribution of these sources is different in each region of the United States. These sources generally include motor vehicle emissions, tire fragments, road dust, industrial and agricultural combustion, wood burning, pollens and molds, forest fires, volcanic emissions, and sea spray [31]. We defined the regions of the United States based on the Census Bureau designated regions [32]: Northeast (CT, ME, MA, NH, NJ, NY, PA, RI, and VT), Midwest (IL, IN, IA, KS, MI, MN, MO, NE, ND, OH, SD, and WI), South (AL, AR, DE, DC, FL, GA, KY, LA, MD, MS, NC, OK, SC, TN, TX, VA, and WV), and West (AZ, CA, CO, ID, MT, NV, NM, OR, UT, WA, and WY). Briefly, predictions of ambient PM were available across the 48 conterminous United States (i.e., all states excluding Alaska and Hawaii). Predictions of monthly average $\mathrm{PM}_{2.5}$ and $\mathrm{PM}_{10}$ were generated using geographic information system (GIS)-based spatio-temporal models to account for spatial and meteorological variation over time [33]. The monthly estimates were linked with participants' residential addresses between 1988 and 2007 [33]. PM 2.5 data were not directly measured before 1999 , and therefore we derived $\mathrm{PM}_{2.5}$ levels before 1999 from the $\mathrm{PM}_{10}$ levels before 1999 using the 1999 ratio of $\mathrm{PM}_{2.5}: \mathrm{PM}_{10}$ [33]. Coarse particulate matter $\left(\mathrm{PM}_{2.5-}\right.$ 10) was calculated as the difference between $\mathrm{PM}_{10}$ and $\mathrm{PM}_{2.5}$ estimates. The models were evaluated for predictive accuracy using a 10-set cross-validation approach; cross-validation correlation coefficients were high for $\mathrm{PM}_{2.5}\left(R^{2}=0.77\right)$ and moderate for $\mathrm{PM}_{10}\left(R^{2}=0.58\right)$ and $\mathrm{PM}_{2.5-10}\left(R^{2}=0.46\right)$ [33].

ii. Proximity to roadways

Secondary exposures of interest included proximity between one's residential address in the year before the mammogram to various types of major roadways as a proxy for traffic-related exposures. For women with a street-segment level geocoded address, proximity of residential address to nearest roadways was calculated in meters using GIS software and the ESRI StreetMap Pro 2007 road network data. Distances to three different types of roadways were classified based on the US Census Feature Class Code road classification system. The types of roadways included: A1 (primary roads, typically interstate highways, with limited access, division between opposing directions of traffic, and defined exits), A2 (primary major, noninterstate highways and major roads without access restrictions), and A3 (smaller, secondary roads, usually with more than two lanes).

\section{Study sample}

To study the influence of PM and proximity to road on normal breast tissue composition, we restricted the analyses to NHS and NHSII participants without breast cancer for whom mammographic density data were available (i.e., controls within the original nested casecontrol studies; $n=2362$ for NHS, $n=1833$ for NHSII). Our analyses were further restricted to women who had a screening film mammogram dated between January 
1990 and December 2008 and those with data available on estimated PM exposures living in the conterminous United States $(n=1821$ for NHS, $n=1815$ for NHSII). Because menopause status and BMI are the strongest predictors of mammographic density, we excluded women with missing or dubious menopause status $(n=$ $308)$ or with missing BMI data $(n=70)$ at the time of mammogram. The final study sample comprised 3258 participants $(n=1624$ premenopausal women; $n=1634$ postmenopausal women).

\section{Covariates}

We considered the following variables in the multivariableadjusted models: cohort/batch (NHS first batch, NHS second batch, NHSII), age at mammogram (years), BMI at mammogram $\left(\mathrm{kg} / \mathrm{m}^{2}\right)$, categories of parity and age at first birth (nulliparous, 1-4 children and age at first birth $<25$ years, $1-4$ children and age at first birth $25-29$ years, $1-4$ children and age at first birth $\geq 30$ years, $\geq 5$ children, missing), categories of hormonal therapy use (never, current, past, missing), history of biopsy-confirmed benign breast disease, age at menopause (for postmenopausal women only), categories of breast feeding status (nulliparous, never breast fed, ever breast fed, missing), age at menarche (years), oral contraceptive use among premenopausal women only (not on oral contraceptives, current for $<5$ years, current for $5+$ years, missing), family history of breast cancer, race/ethnicity (White, Black, Hispanic, Other), BMI at age $18\left(<19 \mathrm{~kg} / \mathrm{m}^{2}, 19-24.9 \mathrm{~kg} / \mathrm{m}^{2}, 25-29.9\right.$ $\mathrm{kg} / \mathrm{m}^{2}, \geq 30 \mathrm{~kg} / \mathrm{m}^{2}$, missing), alcohol consumption (g/day), physical activity (MET hours/week), Census tract-level median house value and median income based on values from the 2000 Census, region of residence (Northeast, Midwest, West, South), and date of mammogram to account for the strong decreasing trends in PM levels over time.

\section{Statistical analyses}

Analyses were carried out separately for women who were premenopausal and postmenopausal at the time of the mammogram. Mammographic density measures were square-root transformed to achieve the statistical assumptions for linear regression. Multivariable linear regression was conducted to estimate the average difference in square-root-transformed breast density measures for a 10$\mu \mathrm{g} / \mathrm{m}^{3}$ increase of $\mathrm{PM}_{2.5}, \mathrm{PM}_{2.5-10}$, and $\mathrm{PM}_{10}$ and to compare previously published categories of residential proximity to $\mathrm{A} 1, \mathrm{~A} 1-\mathrm{A} 2$, and $\mathrm{A} 1-\mathrm{A} 3$ roadways $(<50$ meters, 50-199 meters, and $\geq 200$ meters as the referent group) [30]. In the final multivariable models for premenopausal and postmenopausal women, we included the strongest predictors of mammographic density including cohort/batch, age at mammogram, BMI at mammogram, parity and age at first birth categories, hormonal therapy use, and history of biopsy-confirmed benign breast disease. In sensitivity analyses, we additionally considered other aforementioned covariates. When we present the linear regression estimates for the untransformed mammographic density outcome measures as the dependent variable, bootstrapped robust standard errors are used to calculate $95 \%$ confidence intervals (CIs).

We used the likelihood ratio test (LRT) to determine whether the associations between the exposures and percent density varied by cohort and by region of residence. In addition to the PM results presented across the entire United States, estimates from multivariable models were presented separately for each region. We used nonparametric restricted cubic regression splines [34] to determine whether the associations between PM and percent mammographic density were nonlinear. In sensitivity analyses, we additionally restricted the sample to women who did not move to another state before their mammogram.

All analyses were conducted in SAS version 9.4 (SAS, Cary, NC, USA).

\section{Results}

The 1989 median level of $\mathrm{PM}_{2.5}$ was $16.9 \mu \mathrm{g} / \mathrm{m}^{3}$ (IQR 14.4, 19.5), of $\mathrm{PM}_{2.5-10}$ was $10.6 \mu \mathrm{g} / \mathrm{m}^{3}$ (IQR 8.1, 14.2), and of $\mathrm{PM}_{10}$ was $27.7 \mu \mathrm{g} / \mathrm{m}^{3}$ (IQR 23.8, 32.2). The highest median $\mathrm{PM}_{2.5}$ level was in the Midwest $\left(18.5 \mu \mathrm{g} / \mathrm{m}^{3}\right.$, IQR $16.2,20.5)$ followed by the Northeast $\left(16.6 \mu \mathrm{g} / \mathrm{m}^{3}\right.$, IQR $14.7,18.9)$, the West $\left(15.5 \mu \mathrm{g} / \mathrm{m}^{3}\right.$, IQR $\left.13.4,20.8\right)$, and the South $\left(13.0 \mu \mathrm{g} / \mathrm{m}^{3}\right.$, IQR 11.0, 17.8). The highest median $\mathrm{PM}_{2.5-10}$ level was in the West $\left(19.6 \mu \mathrm{g} / \mathrm{m}^{3}\right.$, IQR $16.4,25.3)$ followed by the South $\left(12.4 \mu \mathrm{g} / \mathrm{m}^{3}\right.$, IQR 10.8 , 13.9), the Midwest $\left(10.8 \mu \mathrm{g} / \mathrm{m}^{3}\right.$, IQR $\left.8.3,14.3\right)$, and the Northeast $\left(8.6 \mu \mathrm{g} / \mathrm{m}^{3}\right.$, IQR $\left.7.1,10.3\right)$. There were no statistically significant interactions with PM exposures and cohort for the multivariable models among premenopausal or among postmenopausal women (LRT $p>0.15$ ).

\section{Premenopausal women}

Premenopausal women $(n=1624)$ in the highest yearadjusted quintiles of $\mathrm{PM}_{2.5} 1$ year before the mammogram were more likely to be overweight/obese at age 18, to have never breast fed, to be current oral contraceptive users, and were less likely to have a history of benign breast disease or family history of breast cancer compared to women in the lowest quintile (Table 1).

Among premenopausal women residing across the United States, no associations were observed between PM exposures and percent mammographic density (Table 2), dense area, or nondense area (see Additional file 1) after multivariable adjustment. The patterns of association between PM and percent density were similar after further adjustment for other covariates and after restricting to women who did not move to another state before the mammogram. The associations were null and not statistically significant comparing premenopausal women who live 
Table 1 Age-standardized characteristics by calendar-year-adjusted PM 2.5 quintiles in premenopausal $(n=1624)$ and postmenopausal $(n=1634)$ participants

\begin{tabular}{|c|c|c|c|c|}
\hline \multirow[b]{2}{*}{ Characteristic $^{a}$} & \multicolumn{2}{|c|}{ Premenopausal women } & \multicolumn{2}{|c|}{ Postmenopausal women } \\
\hline & $\begin{array}{l}\text { 1st quintile } \\
(n=331)\end{array}$ & $\begin{array}{l}\text { 5th quintile } \\
(n=332)\end{array}$ & $\begin{array}{l}\text { 1st quintile } \\
(n=331)\end{array}$ & $\begin{array}{l}\text { 5th quintile } \\
(n=334)\end{array}$ \\
\hline Age at mammogram ${ }^{b}$ & $45.6 \pm 4.2$ & $45.6 \pm 4.3$ & $60.0 \pm 7.4$ & $59.7 \pm 7.6$ \\
\hline NHSII cohort (\%) & 76 & 78 & 19 & 24 \\
\hline BMl at mammogram $\left(\mathrm{kg} / \mathrm{m}^{2}\right)$ & $25.1 \pm 5.6$ & $25.8 \pm 5.5$ & $26.1 \pm 5.0$ & $26.5 \pm 5.6$ \\
\hline Presence of biopsy-confirmed benign breast disease (\%) & 18.8 & 17.8 & 23.4 & 21.8 \\
\hline Current use of hormonal therapy (\%) & 2.7 & 2.3 & 52.2 & 47.3 \\
\hline \multicolumn{5}{|l|}{ Parity and age at first birth status (\%) } \\
\hline Nulliparous & 16.3 & 16.5 & 9.8 & 9.8 \\
\hline 1-4 children before age 25 & 29.0 & 29.3 & 36.5 & 38.2 \\
\hline 1-4 children between age 25 and 30 & 33.8 & 34.4 & 31.9 & 29.5 \\
\hline 1-4 children after age 30 & 17.7 & 17.0 & 8.6 & 9.8 \\
\hline $5+$ children & 2.6 & 1.9 & 12.6 & 11.7 \\
\hline Missing & 0.6 & 0.9 & 0.5 & 1.0 \\
\hline \multicolumn{5}{|l|}{ Categories of BMl at age 18 (\%) } \\
\hline$<19.0 \mathrm{~kg} / \mathrm{m}^{2}$ & 16.0 & 17.8 & 10.6 & 13.3 \\
\hline $19.0-24.9 \mathrm{~kg} / \mathrm{m}^{2}$ & 72.2 & 70.7 & 75.6 & 72.9 \\
\hline $25-29.9 \mathrm{~kg} / \mathrm{m}^{2}$ & 7.4 & 8.5 & 9.4 & 8.1 \\
\hline $30+\mathrm{kg} / \mathrm{m}^{2}$ & 1.9 & 1.7 & 0.9 & 1.9 \\
\hline Missing & 2.5 & 1.3 & 3.5 & 3.8 \\
\hline Family history of breast cancer (\%) & 10.7 & 8.5 & 13.0 & 11.0 \\
\hline Age at menarche (years) & $12.4 \pm 1.4$ & $12.4 \pm 1.4$ & $12.4 \pm 1.3$ & $12.6 \pm 1.5$ \\
\hline \multicolumn{5}{|l|}{ Lactation among parous women (\%) } \\
\hline Never breastfed & 15.0 & 21.9 & 35.8 & 41.5 \\
\hline Yes, breastfed > 1 month & 82.5 & 75.1 & 62.8 & 57.0 \\
\hline Missing & 2.5 & 3.1 & 1.5 & 1.3 \\
\hline \multicolumn{5}{|l|}{ Oral contraceptive use (\%) } \\
\hline Not on oral contraceptives & 94.4 & 93.4 & - & - \\
\hline Current $<5$ years & 2.6 & 1.5 & - & - \\
\hline Current $5+$ years & 2.7 & 4.9 & - & - \\
\hline Missing & 0.3 & 0.3 & - & - \\
\hline Alcohol consumption (g/day) & $5.3 \pm 8.4$ & $3.8 \pm 6.3$ & $5.6 \pm 9.1$ & $4.8 \pm 8.1$ \\
\hline Physical activity (MET hours/week) & $22.2 \pm 29.6$ & $17.5 \pm 19.2$ & $17.6 \pm 17.3$ & $19.4 \pm 26.3$ \\
\hline White (\%) & 99.4 & 97.5 & 98.6 & 97.7 \\
\hline \multicolumn{5}{|l|}{ Region of residence (\%) } \\
\hline Northeast & 27.8 & 27.4 & 28.0 & 33.4 \\
\hline Midwest & 13.8 & 40.5 & 6.5 & 34.8 \\
\hline West & 39.4 & 16.5 & 33.8 & 20.6 \\
\hline South & 18.9 & 15.6 & 31.7 & 11.2 \\
\hline Distance from residential address to A1-A3 roadways (meters) & $313.8 \pm 185.9$ & $231.1 \pm 169.6$ & $299.0 \pm 187.5$ & $220.2 \pm 168.1$ \\
\hline
\end{tabular}

$P M_{2.5}$ particulate matter less than $2.5 \mu \mathrm{m}$ in diameter, NHSII Nurses' Health Study II, BMI body mass index, MET metabolic equivalent

${ }^{a}$ Values are mean \pm SD or percentages and are standardized to the age distribution of the study population. Values of polytomous variables may not sum to $100 \%$ due to rounding

${ }^{b}$ Value is not age adjusted 
Table 2 Estimated differences ${ }^{a}$ (95\% confidence interval) in square-root-transformed percent mammographic density for a $10-\mu \mathrm{g} / \mathrm{m}^{3}$ PM increase

\begin{tabular}{|c|c|c|c|c|c|c|}
\hline & Across the United States & Northeast & Midwest & West & South & $\begin{array}{l}p \text { for region } \\
\text { interaction term }\end{array}$ \\
\hline \multicolumn{7}{|l|}{ Premenopausal } \\
\hline 1 year prior & $n=1624$ & $n=577$ & $n=554$ & $n=261$ & $n=232$ & \\
\hline $\mathrm{PM}_{2.5}$ & $0.04(-0.17,0.26)$ & $0.06(-0.40,0.52)$ & $-0.08(-0.58,0.43)$ & $0(-0.35,0.34)$ & $0.21(-0.32,0.74)$ & 0.59 \\
\hline $\mathrm{PM}_{2.5-10}$ & $-0.01(-0.16,0.15)$ & $-0.01(-0.57,0.54)$ & $-0.07(-0.42,0.28)$ & $0.08(-0.19,0.34)$ & $-0.34(-0.95,0.27)$ & 0.45 \\
\hline $\mathrm{PM}_{10}$ & $0.01(-0.10,0.12)$ & $0.02(-0.26,0.30)$ & $-0.06(-0.33,0.20)$ & $0.03(-0.14,0.20)$ & $-0.05(-0.57,0.47)$ & 0.58 \\
\hline 3-year average & $n=1624$ & $n=582$ & $n=554$ & $n=260$ & $n=228$ & \\
\hline $\mathrm{PM}_{2.5}$ & $0.05(-0.16,0.27)$ & $0.05(-0.40,0.51)$ & $-0.05(-0.55,0.45)$ & $-0.01(-0.36,0.35)$ & $0.27(-0.27,0.81)$ & 0.53 \\
\hline $\mathrm{PM}_{2.5-10}$ & $0(-0.15,0.16)$ & $0.02(-0.53,0.57)$ & $-0.04(-0.40,0.33)$ & $0.10(-0.18,0.38)$ & $-0.58(-1.19,0.03)$ & 0.22 \\
\hline $\mathrm{PM}_{10}$ & $0.02(-0.10,0.13)$ & $0.02(-0.25,0.30)$ & $-0.03(-0.30,0.23)$ & $0.04(-0.13,0.20)$ & $-0.17(-0.70,0.36)$ & 0.67 \\
\hline \multicolumn{7}{|l|}{ Postmenopausal } \\
\hline 1 year prior & $n=1634$ & $n=738$ & $n=360$ & $n=274$ & $n=262$ & \\
\hline $\mathrm{PM}_{2.5}$ & $-0.04(-0.26,0.19)$ & $0.37(-0.03,0.77)$ & $-0.24(-0.91,0.42)$ & $-0.21(-0.56,0.13)$ & $-0.05(-0.70,0.60)$ & 0.09 \\
\hline $\mathrm{PM}_{2.5-10}$ & $-0.01(-0.16,0.14)$ & $0.22(-0.24,0.69)$ & $0.11(-0.38,0.60)$ & $-0.22(-0.47,0.03)$ & $0.32(-0.32,0.96)$ & 0.29 \\
\hline $\mathrm{PM}_{10}$ & $-0.01(-0.12,0.10)$ & $0.19(-0.05,0.42)$ & $-0.01(-0.34,0.32)$ & $-0.14(-0.29,0.02)$ & $0.19(-0.35,0.74)$ & 0.15 \\
\hline 3-year average & $n=1634$ & $n=745$ & $n=364$ & $n=272$ & $n=253$ & \\
\hline $\mathrm{PM}_{2.5}$ & $-0.05(-0.27,0.17)$ & $0.39(-0.02,0.79)$ & $-0.25(-0.91,0.42)$ & $-0.27(-0.62,0.07)$ & $0.06(-0.61,0.73)$ & 0.06 \\
\hline $\mathrm{PM}_{2.5-10}$ & $-0.01(-0.16,0.14)$ & $0.19(-0.27,0.65)$ & $0.16(-0.32,0.64)$ & $-0.23(-0.47,0.02)$ & $0.39(-0.30,1.07)$ & 0.24 \\
\hline $\mathrm{PM}_{10}$ & $-0.02(-0.13,0.09)$ & $0.18(-0.06,0.41)$ & $0.02(-0.31,0.34)$ & $-0.15(-0.31,0.01)$ & $0.31(-0.26,0.89)$ & 0.10 \\
\hline
\end{tabular}

$P M$ particulate matter, $P M_{2.5}$ particulate matter less than $2.5 \mu \mathrm{m}$ in diameter, $P M_{2.5-10}$ particulate matter between 2.5 and $10 \mu \mathrm{m}$ in diameter, $P M_{10}$ particulate matter less than $10 \mu \mathrm{m}$ in diameter

${ }^{a}$ Adjusted for cohort, age, body mass index, parity and age at first birth categories, hormonal therapy use, history of biopsy-confirmed benign breast disease, and date of mammogram

closer to roadways to those who live further away (Table 3). There was no evidence for a nonlinear relationship between PM and percent mammographic density.

\section{Postmenopausal women}

Postmenopausal women $(n=1634)$ in the highest yearadjusted quintiles of $\mathrm{PM}_{2.5} 1$ year before the mammogram were similar in terms of most mammographic density predictors compared to women in the lowest quintile (Table 1). However, women in the highest quintile were more likely to have never used hormonal therapy or lactated and were less likely to have had a history of benign breast disease and family history of breast cancer compared to women in the lowest quintile.

There were no associations between PM exposures or proximity to roadways and mammographic density outcomes for postmenopausal women overall (Tables 2 and 3; see Additional file 1: Table S1 for dense and nondense area outcomes). We did observe borderline statistically significant interactions between region and $\mathrm{PM}_{2.5}$ and $\mathrm{PM}_{10}$ levels with percent density (Table 2, $p$ for interaction with region $<0.10$ ). Among postmenopausal women in the Midwest and the South, the results were null and not statistically significant for PM exposures and density measures (Table 2; see Additional file 1: Table S1 for dense and nondense area outcomes).

Among postmenopausal women in the West, there were no statistically significant associations between $\mathrm{PM}_{2.5}$ and transformed mammographic density measures; however, suggestive inverse associations were observed for $\mathrm{PM}_{2.5-10}$ with percent density $(\beta=-0.23,95 \% \mathrm{CI}-0.47,0.02$; Table 2), although the $p$ value for interaction between $\mathrm{PM}_{2.5-10}$ and region was not statistically significant ( $p$ for interaction $=0.24$ ). For the estimates of untransformed percent mammographic density, a $10-\mu \mathrm{g} / \mathrm{m}^{3}$ increase in cumulative $\mathrm{PM}_{2.5-10}$ up to 3 years before the mammogram was associated with an average difference of -2.0 percentage points (95\% CI -4.7, 0.6; Additional file 1: Table S2). The patterns of association for postmenopausal PM results in the West did not change meaningfully after additional adjustment of other covariates or after restricting to nonmovers.

In contrast among postmenopausal women in the Northeast, there were no statistically significant associations between $\mathrm{PM}_{2.5-10}$ and transformed mammographic density measures (Table 2; see Additional file 1: Table S1 for dense and nondense area measures); however, there were suggestive positive associations between $\mathrm{PM}_{2.5}$ and transformed percent mammographic density $(\beta=0.39,95 \%$ CI -0.02 , 
Table 3 Estimated differences ${ }^{\mathrm{a}}$ (95\% confidence interval) in square-root-transformed percent mammographic density by distance to roadways.

\begin{tabular}{|c|c|c|c|c|c|c|}
\hline & $n$ & Premenopausal & $\begin{array}{l}p \text { for region } \\
\text { interaction term }\end{array}$ & $n$ & Postmenopausal & $\begin{array}{l}p \text { for region } \\
\text { interaction term }\end{array}$ \\
\hline \multicolumn{7}{|l|}{ Distance to $A 1$ roads } \\
\hline$\geq 200$ meters & 1576 & Referent & 0.95 & 1598 & Referent & 0.001 \\
\hline$<200$ meters & 47 & $-0.25(-0.65,0.15)$ & & 36 & $0.10(-0.39,0.60)$ & \\
\hline$p$ value & & 0.22 & & & 0.68 & \\
\hline Distance to $\mathrm{A} 1-\mathrm{A} 2$ roads & & & 0.90 & & & 0.48 \\
\hline$\geq 200$ meters & 1500 & Referent & & 1510 & Referent & \\
\hline 50-199 meters & 87 & $-0.13(-0.43,0.16)$ & & 84 & $-0.03(-0.35,0.30)$ & \\
\hline$<50$ meters & 36 & $0.06(-0.39,0.51)$ & & 40 & $-0.12(-0.59,0.35)$ & \\
\hline$p$ trend & & 0.65 & & & 0.88 & \\
\hline Distance to $\mathrm{A} 1-\mathrm{A} 3$ roads & & & 0.43 & & & 0.47 \\
\hline$\geq 200$ meters & 978 & Referent & & 936 & Referent & \\
\hline 50-199 meters & 413 & $-0.05(-0.21,0.11)$ & & 431 & $-0.16(-0.33,0.01)$ & \\
\hline$<50$ meters & 232 & $0.03(-0.17,0.23)$ & & 267 & $-0.11(-0.31,0.10)$ & \\
\hline$p$ trend & & 0.73 & & & 0.17 & \\
\hline
\end{tabular}

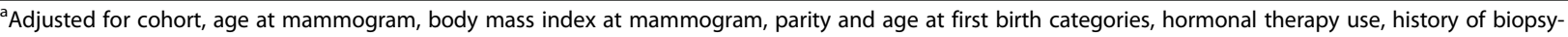
confirmed benign breast disease, and date of mammogram

0.79; Table 2) and significant inverse associations with transformed nondense area $(\beta=-0.76,95 \% \mathrm{CI}-1.41$, 0.11; see Additional file 1: Table S1). For the estimates of untransformed mammographic density measures, a 10- $\mu \mathrm{g} /$ $\mathrm{m}^{3}$ increase in 3-year cumulative $\mathrm{PM}_{2.5}$ in the Northeast was associated with an average difference in percent mammographic density of 3.4 percentage points $(95 \% \mathrm{CI}-0.5$, 7.3; Additional file 1: Table S2) and an average difference in nondense area of $-17.2 \mathrm{~cm}^{2}$ (95\% CI $-36.1,-0.5$; Additional file 1: Table S2). The associations did not change meaningfully after further adjustment for other covariates or after restricting to nonmovers. There was no evidence for a nonlinear relationship between PM and percent mammographic density.

\section{Discussion}

In summary, we observed no overall association between residential PM exposures or proximity to roadways and mammographic density in premenopausal and postmenopausal women residing across the conterminous United States. This is consistent with the reported null overall associations between PM and breast cancer incidence in prospective cohort studies from the Danish Nurse Cohort, the NHSII, and the Sister Study Cohort [17-19]. Upon further exploration, we did observe differences in associations with PM exposures and mammographic density by region of the United States among postmenopausal women. Recent exposure to fine particulate matter $\left(\mathrm{PM}_{2.5}\right)$ in the Northeast was associated with a percent mammographic density 3.4 percentage points higher percent mammographic density (95\% CI -0.5, 7.3) among postmenopausal women.
Unexpectedly, recent coarse particulate matter $\left(\mathrm{PM}_{2.5-10}\right)$ in the West showed a weaker, inverse association with percent density $(-2.0$ percentage point difference, $95 \% \mathrm{CI}-4.7$, $0.6)$.

Three studies based in Denmark, in the Netherlands, and in five registries in the US Breast Cancer Surveillance Consortium (New Hampshire, Vermont, New Mexico, San Francisco, and western Washington) reported inconsistent findings between air pollution exposures and mammographic density [21-23], potentially due to different measurements and distributions of mammographic density and air pollution. In Denmark [22], the authors found a weak inverse association between having mixed/dense breasts and residential exposure to nitrogen oxide that did not differ by menopausal status, but did not assess PM or continuous measures of mammographic density. In the Dutch study of primarily postmenopausal women [21], there were small positive associations observed between continuous percent mammographic density and residential nitrogen dioxide and $\mathrm{PM}_{2.5}$ absorbance but null associations for small increases in $\mathrm{PM}_{2.5}, \mathrm{PM}_{2.5-10}$, and $\mathrm{PM}_{10}$ exposures. In the five registries in the US-based Breast Cancer Surveillance Consortium [23], $\mathrm{PM}_{2.5}$ at the participants' zip code was positively associated with categorical measures of mammographic density based on the American College of Radiology's Breast Imaging-Reporting and Data System (BI-RADS) categories. In addition to the methodologic differences in measurement of mammographic density and air pollution across previous studies, the inconsistent findings suggest that geospatial variation in air pollution composition may account for the different findings in 
Denmark, the Netherlands, and the United States. In the current study, we observed regional differences among postmenopausal women with positive associations between $\mathrm{PM}_{2.5}$ and mammographic density in the Northeastern United States, but null findings between $\mathrm{PM}_{2.5}$ and mammographic density in the Midwest, South, and West. Regional differences have also been noted in cardiovascular disease outcomes, with stronger associations with $\mathrm{PM}_{2.5}$ in the Northeast [35]. This may be in part due to the differences in $\mathrm{PM}_{2.5}$ levels, composition, and sources across regions in the United States.

Fine particles $\left(\mathrm{PM}_{2.5}\right)$ are primarily from combustion sources, organic compounds, and metals that can penetrate the small airways and alveoli deep in the lung [31] and have an atmospheric half-life ranging from days to weeks [36]. In the United States, approximately $80 \%$ of $\mathrm{PM}_{2.5}$ composition consists of sulfates, nitrates, ammonium, elemental carbon, organic carbon, $\mathrm{Na}^{+}$, and silicon and the remaining $\sim 20 \%$ is a catch-all category consisting largely of many minerals and metals (e.g., $\mathrm{Pb}, \mathrm{Cd}, \mathrm{V}$, $\mathrm{Ni}, \mathrm{Cu}, \mathrm{Zn}, \mathrm{Mn}$, and $\mathrm{Fe}$ ); however, the distribution of these major components differs across the United States [36, 37]. In the Eastern United States, the proportions of sulfate, ammonium, and the catch-all category for other constituents were higher than in the Western United States, with larger differences in summer, whereas $\mathrm{PM}_{2.5}$ composition in the Western United States was higher in organic carbon, elemental carbon, nitrates, and silicon [36, 37]. Furthermore, $\mathrm{PM}_{2.5}$ levels were highest in the Eastern United States [36, 37], particularly in the Northeast [37]. The EPA describes in detail the formation, composition, and sources of $\mathrm{PM}_{2.5}$ and $\mathrm{PM}_{2.5-10}$ [36]. The biological effects of exposure to PM appear to go beyond the lung inducing systemic inflammation, oxidative stress, and epigenetic changes seen with alterations in circulating $\mathrm{C}$-reactive protein, fibrinogen, white blood cell counts, tumor necrosis factor alpha, interleukin-6, DNA adducts, protein, lipids and DNA oxidation [38], and DNA methylation [39, 40]. Taken together, the higher levels and more heterogeneous composition of $\mathrm{PM}_{2.5}$ in the Northeast than in other regions as well as the half-life and biological plausibility of $\mathrm{PM}_{2.5}$ to induce systemic changes may be germane to variation in breast tissue composition seen only with $\mathrm{PM}_{2.5}$ among postmenopausal women residing in the Northeast. Future studies of PM and postmenopausal breast cancer risk should be aware of the differences in PM composition across regions of the United States.

While we observed largely null $\mathrm{PM}_{2.5-10}$ associations, the inverse associations between coarse $\mathrm{PM}_{2.5-10}$ and percent mammographic density among postmenopausal women in the West were surprising, were lacking in biological plausibility, and were likely due to the greater uncertainty inherent in the $\mathrm{PM}_{2.5-10}$ measurements or chance. $\mathrm{PM}_{2.5-10}$ is formed by the break-up of large solids and droplets (e.g., crushing, grinding and abrasion of surfaces, dust suspension, and the evaporation of ocean sprays) and is largely composed of soil, street dust, fly ash from uncontrolled combustion, nitrates, sulfates, crustal oxides ( $\mathrm{Si}, \mathrm{Al}$, and $\mathrm{Fe})$, sea salt, pollen, fungal spores, insect fragments, other bioaerosols, and automobile debris. The atmospheric half-life of $\mathrm{PM}_{2.5-10}$ is shorter than that of $\mathrm{PM}_{2.5}$ ranging from minutes to hours and $\mathrm{PM}_{2.5-10}$ can penetrate the extrathoracic and upper tracheobronchial regions [36]. Compared to the $\mathrm{PM}_{2.5}$ measurement estimations, coarse $\mathrm{PM}_{2.5-10}$ estimates had lower cross-validation $R^{2}$ coefficients across all US regions $\left(\mathrm{PM}_{2.5} R^{2}=0.77\right.$ versus $\mathrm{PM}_{2.5-10} R^{2}=$ $0.46)$ and within regions $\left(\mathrm{PM}_{2.5}\right.$ in Southwest $R^{2}=0.77$, Northwest $R^{2}=0.56$, Northeast $R^{2}=0.72$ versus $\mathrm{PM}_{2.5-10}$ in Southwest $R^{2}=0.53$, Northwest $R^{2}=0.54$, Northeast $R^{2}=0.32$ ), which suggests that $\mathrm{PM}_{2.5-10}$ estimates had more error on average than $\mathrm{PM}_{2.5}$ estimates [33].

There are several limitations and strengths of the study. Exposure measurement error is often a challenge. Several types of error can contribute to measurement error of PM. Instead of collecting personal exposure data that are not feasible on a large epidemiologic scale, we used predictions from spatio-temporal modeling. These data are subject to both Berkson error, which results in imprecision, and classical error that usually results in attenuated estimates toward the null $[41,42]$. A combination of these errors could be the reason for the largely null findings. Furthermore, PM has many constituents $[43,44]$ and while the complex mixture of constituents was largely not associated with mammographic density, one cannot rule out that certain constituents may have an effect that was not captured by our measures of PM. While we did observe suggestive subgroup findings among postmenopausal women, it is possible that chance may explain the subgroup findings. Another limitation of the study's exposure assessment is the inability to incorporate time spent at the residence or the time spent exposed to outdoor air pollution at the residence, and data on other ambient air pollutants such as $\mathrm{NO}_{\mathrm{x}} / \mathrm{NO}_{2}$ were not available in these cohorts. In this study, we used spatio-temporal PM modeling that can reduce classical error; this technique has been reported to be more strongly correlated with personal PM exposure than using PM values from a nearest monitor [41]. Lastly, we were able to investigate the relationship of recent PM exposures; however, recent environmental exposures may not be the most relevant time window of exposure as research is pointing to the importance of early life exposures around the time of puberty and a woman's first birth [45-48]. In spite of the limitations inherent in the exposure assessment, the strengths of the study included using a model of PM estimates that have been associated with other health conditions in this cohort, including mortality, cardiovascular 
disease, lung cancer, hypertension, pulmonary embolism, and cognitive decline [30, 49-54]. Furthermore, the study was conducted among women residing across the conterminous United States, making it the most geographically expansive study of mammographic density and air pollution to date. The large size of the study allowed for stratified analyses to explore the associations separately for premenopausal and postmenopausal women and to assess regional variations in the associations of PM and mammographic density. Lastly, many of the known predictors of mammographic density were considered to control for potential confounding.

\section{Conclusions}

This study does not provide evidence that PM in the United States is associated with breast density variation. However, there is suggestive evidence that fine PM in the Northeast United States may influence breast tissue composition for postmenopausal women. Furthermore, this study cannot rule out the potential relationship of PM exposures during earlier time windows of exposure and mammographic density.

\section{Additional file}

Additional file 1: Table S1. Presenting adjusted estimates $(95 \% \mathrm{Cl})$ of the difference in square-root-transformed mammographic dense area and nondense area for a $10-\mu \mathrm{g} / \mathrm{m}^{3}$ increase in PM among premenopausal and postmenopausal women residing across the United States and within regions, and Table S2. presenting adjusted estimates $(95 \% \mathrm{Cl})$ of the difference in untransformed mammographic density measures for a $10-\mu \mathrm{g} / \mathrm{m}^{3}$ increase in PM using bootstrapped robust standard errors (DOCX $33 \mathrm{~kb}$ )

\section{Abbreviations}

BI-RADS: Breast Imaging-Reporting and Data System; BMI: Body mass index; Cl: Confidence interval; EPA: Environmental Protection Agency;

GIS: Geographic information system; IQR: Interquartile range; LRT: Likelihood ratio test; NHS: Nurses' Health Study; NHSII: Nurses' Health Study II; PM: Particulate matter $\left(\mathrm{PM}_{2.5}, \mathrm{PM}_{2.5-10}\right.$, and $\left.\mathrm{PM}_{10}\right)$

\section{Acknowledgements}

The authors would like to thank the participants of the Nurses' Health Study and Nurses' Health Study II for their continuing contributions.

\section{Funding}

This study was supported by research grants UM1 CA186107, UM1 CA176726, and ES017017, National Institute of Health Epidemiology Education Training Grant (NIH T32 CA09001), the Breast Cancer Research Foundation, and Susan G. Komen for the Cure ${ }^{\oplus}$ grant IIR13264020.

\section{Availability of data and materials}

The dataset analyzed in the current study is available from the corresponding author on reasonable request.

\section{Authors' contributions}

NCD analyzed the data and was a major contributor in writing the manuscript. All authors (NCD, JEH, KAB, PK, FL, RMT) interpreted the data, contributed to the scientific development, and edited, read, and approved the final manuscript. Additionally, JEH and FL developed the exposure models. RMT and FL proposed the study design.

\section{Ethics approval and consent to participate}

Participants provided implied consent through return of questionnaires, and informed consent was obtained to collect mammograms. This study was approved by the Committee on the Use of Human Subjects in Research at the Brigham and Women's Hospital.

\section{Consent for publication}

Not applicable.

\section{Competing interests}

The authors declare that they have no competing interests.

\section{Publisher's Note}

Springer Nature remains neutral with regard to jurisdictional claims in published maps and institutional affiliations.

\section{Author details}

${ }^{1}$ Department of Epidemiology, Harvard T.H. Chan School of Public Health, Boston, MA, USA. ${ }^{2}$ Channing Division of Network Medicine, Department of Medicine, Brigham and Women's Hospital and Harvard Medical School, Boston, MA, USA. ${ }^{3}$ Department of Environmental Health, Harvard T.H. Chan School of Public Health, Boston, MA, USA. ${ }^{4}$ Slone Epidemiology Center at Boston University, Boston, MA, USA.

Received: 16 August 2017 Accepted: 7 November 2017

Published online: 23 November 2017

\section{References}

1. National Center for Health Statistics (US). Health, United States, With Special Feature on Adults Aged 55-64. Hyattsville: National Center for Health Statistics; 2014. p. 2015. http://www.ncbi.nlm.nih.gov/books/NBK299348/. Accessed 26 Feb 2016

2. McCormack VA, dos Santos Silva I. Breast density and parenchymal patterns as markers of breast cancer risk: a meta-analysis. Cancer Epidemiol Biomarkers Prev. 2006:15:1159-69.

3. Rice MS, Bertrand KA, VanderWeele TJ, Rosner BA, Liao X, Adami H-O, et al. Mammographic density and breast cancer risk: a mediation analysis. Breast Cancer Res. 2016;18:94.

4. Martin LJ, Boyd NF. Mammographic density. Potential mechanisms of breast cancer risk associated with mammographic density: hypotheses based on epidemiological evidence. Breast Cancer Res. 2008;10:201.

5. De Coster S, van Larebeke N. Endocrine-disrupting chemicals: associated disorders and mechanisms of action. J Environ Public Health. 2012;2012:713696.

6. Carré J, Gatimel N, Moreau J, Parinaud J, Léandri R. Does air pollution play a role in infertility?: a systematic review. Environ Health. 2017;16:82.

7. IARC (International Agency for Research on Cancer). Outdoor air pollution IARC Monographs on the Evaluation of Carcinogenic Risks to Humans 109, vol. 109. Lyon: WHO International Agency for Research on Cancer (IARC): 2015. p. 431-44. http://monographs.iarc.fr/ENG/Monographs/vol109/ mono109.pdf. Accessed 17 Nov 2017.

8. Gammon MD, Santella RM, Neugut Al, Eng SM, Teitelbaum SL, Paykin A, et al. Environmental toxins and breast cancer on Long Island. I. Polycyclic aromatic hydrocarbon DNA adducts. Cancer Epidemiol Biomarkers Prev. 2002;11:677-85.

9. Labrèche F, Goldberg MS, Valois M-F, Nadon L. Postmenopausal breast cancer and occupational exposures. Occup Environ Med. 2010;67:263-9.

10. Petralia SA, Vena JE, Freudenheim JL, Dosemeci M, Michalek A, Goldberg MS, et al. Risk of premenopausal breast cancer in association with occupational exposure to polycyclic aromatic hydrocarbons and benzene. Scand J Work Environ Health. 1999;25:215-21.

11. Chen F, Bina WF. Correlation of white female breast cancer incidence trends with nitrogen dioxide emission levels and motor vehicle density patterns. Breast Cancer Res Treat. 2012;132:327-33.

12. Lewis-Michl EL, Melius JM, Kallenbach LR, Ju CL, Talbot TO, Orr MF, et al. Breast cancer risk and residence near industry or traffic in Nassau and Suffolk Counties, Long Island. New York Arch Environ Health. 1996;51:255-65.

13. Gorham ED, Garland CF, Garland FC. Acid haze air pollution and breast and colon cancer mortality in 20 Canadian cities. Can J Public Health. 1989;80:96-100

14. Crouse DL, Goldberg MS, Ross NA, Chen H, Labrèche F. Postmenopausal breast cancer is associated with exposure to traffic- 
related air pollution in Montreal, Canada: a case-control study. Environ Health Perspect. 2010;118:1578-83.

15. Bonner MR, Han D, Nie J, Rogerson P, Vena JE, Muti P, et al. Breast cancer risk and exposure in early life to polycyclic aromatic hydrocarbons using total suspended particulates as a proxy measure. Cancer Epidemiol Biomarkers Prev. 2005;14:53-60.

16. Nie J, Beyea J, Bonner MR, Han D, Vena JE, Rogerson P, et al. Exposure to traffic emissions throughout life and risk of breast cancer: the Western New York Exposures and Breast Cancer (WEB) study. Cancer Causes Control. 2007;18:947-55.

17. Andersen ZJ, Ravnskjaer L, Andersen KK, Loft S, Brandt J, Becker T, et al. Long-term exposure to fine particulate matter and breast cancer incidence in the Danish Nurse Cohort Study. Cancer Epidemiol Biomarkers Prev. 2016; 26:428-30.

18. Hart JE, Bertrand KA, DuPre N, James P, Vieira VM, Tamimi RM, et al. Longterm particulate matter exposures during adulthood and risk of breast cancer incidence in the Nurses' Health Study II prospective cohort. Cancer Epidemiol Biomarkers Prev. 2016;25:1274-6.

19. Reding KW, Young MT, Szpiro AA, Han CJ, DeRoo LA, Weinberg C, et al. Breast cancer risk in relation to ambient air pollution exposure at residences in the Sister Study Cohort. Cancer Epidemiol Biomarkers Prev. 2015;24:1907-9.

20. IOM (Institute of Medicine). Breast cancer and the environment: a life course approach. Washington, DC: The National Academies Press; 2012.

21. Emaus MJ, Bakker MF, Beelen RMJ, Veldhuis WB, Peeters PHM, van Gils CH. Degree of urbanization and mammographic density in Dutch breast cancer screening participants: results from the EPIC-NL cohort. Breast Cancer Res Treat. 2014;148:655-63.

22. Huynh S, von Euler-Chelpin M, Raaschou-Nielsen O, Hertel O, Tjønneland A, Lynge $\mathrm{E}$, et al. Long-term exposure to air pollution and mammographic density in the Danish Diet, Cancer and Health cohort. Environ Health. 2015;14:31.

23. Yaghjyan L, Arao R, Brokamp C, O'Meara ES, Sprague BL, Ghita G, et al. Association between air pollution and mammographic breast density in the Breast Cancer Surveilance Consortium. Breast Cancer Res. 2017;19:36.

24. Colditz GA, Hankinson SE. The Nurses' Health Study: lifestyle and health among women. Nat Rev Cancer. 2005;5:388-96.

25. Tamimi RM, Hankinson SE, Colditz GA, Byrne C. Endogenous sex hormone levels and mammographic density among postmenopausal women. Cancer Epidemiol Biomarkers Prev. 2005;14:2641-7.

26. Bertrand KA, Eliassen AH, Hankinson SE, Gierach GL, Xu X, Rosner B, et al. Urinary estrogens and estrogen metabolites and mammographic density in premenopausal women. Breast Cancer Res Treat. 2012;136:277-87.

27. Rice MS, Rosber BA, Tamimi RM. Percent mammographic density prediction: development of a model in the nurses' health studies. Cancer Causes Control. 2017;7:677-84.

28. Yaghjyan L, Pettersson A, Colditz GA, Collins LC, Schnitt SJ, Beck AH, et al. Postmenopausal mammographic breast density and subsequent breast cancer risk according to selected tissue markers. Br J Cancer. 2015;113:1104-13.

29. Rice MS, Tworoger SS, Bertrand KA, Hankinson SE, Rosner BA, Feeney YB, et al. Immunoassay and Nb2 lymphoma bioassay prolactin levels and mammographic density in premenopausal and postmenopausal women the Nurses' Health Studies. Breast Cancer Res Treat. 2015;149:245-53.

30. Puett RC, Hart JE, Yanosky JD, Spiegelman D, Wang M, Fisher JA, et al. Particulate matter air pollution exposure, distance to road, and incident lung cancer in the nurses' health study cohort. Environ Health Perspect. 2014;122:926-32

31. Brook RD, Franklin B, Cascio W, Hong Y, Howard G, Lipsett M, et al. Air pollution and cardiovascular disease: a statement for healthcare professionals from the Expert Panel on Population and Prevention Science of the American Heart Association. Circulation. 2004;109:2655-71.

32. U.S. Department of Commerce Economics and Statistics Administration U.S. Census Bureau. Census Regions and Divisions of the United States. http:// www2.census.gov/geo/pdfs/maps-data/maps/reference/us_regdiv.pdf. Accessed 31 Oct 2016.

33. Yanosky JD, Paciorek CJ, Laden F, Hart JE, Puett RC, Liao D, et al. Spatiotemporal modeling of particulate air pollution in the conterminous United States using geographic and meteorological predictors. Environ Health. 2014;13:63.

34. Durrleman S, Simon R. Flexible regression models with cubic splines. Stat Med. 1989;8:551-61.
35. Dominici F, Peng RD, Bell ML, Pham L, McDermott A, Zeger SL, et al. Fine particulate air pollution and hospital admission for cardiovascular and respiratory diseases. JAMA. 2006;295:1127-34.

36. National Center for Environmental Assessment. Air Quality Criteria for Particulate Matter (Volumes I and II). Research Triangle Park, NC: US Environmental Protection Agency; 2004

37. Bell ML, Dominici F, Ebisu K, Zeger SL, Samet JM. Spatial and temporal variation in PM2.5 chemical composition in the United States for health effects studies. Environ Health Perspect. 2007;115:989-95.

38. Brook RD, Urch B, Dvonch JT, Bard RL, Speck M, Keeler G, et al. Insights into the mechanisms and mediators of the effects of air pollution exposure on blood pressure and vascular function in healthy humans. Hypertension. 2009;54:659-67.

39. Guo L, Byun H-M, Zhong J, Motta V, Barupal J, Zheng Y, et al. Effects of short-term exposure to inhalable particulate matter on DNA methylation of tandem repeats. Environ Mol Mutagen. 2014:55:322-35.

40. Panni T, Mehta AJ, Schwartz JD, Baccarelli AA, Just AC, Wolf K, et al. A genome-wide analysis of DNA Methylation and fine particulate matter air pollution in three study populations: KORA F3, KORA F4, and the Normative Aging Study. Environ Health Perspect. 2016;124:983-90.

41. Kioumourtzoglou M-A, Spiegelman D, Szpiro AA, Sheppard L, Kaufman JD, Yanosky JD, et al. Exposure measurement error in PM2.5 health effects studies: a pooled analysis of eight personal exposure validation studies. Environ Health. 2014;13:2.

42. Zeger SL, Thomas D, Dominici F, Samet JM, Schwartz J, Dockery D, et al. Exposure measurement error in time-series studies of air pollution: concepts and consequences. Environ Health Perspect. 2000;108:419-26.

43. Bell ML. Assessment of the Health Impacts of Particulate Matter Characteristics. Research Report 161. Jan 2012. Health Effects Institute, Boston, MA.

44. Chung Y, Dominici F, Wang Y, Coull BA, Bell ML. Associations between long-term exposure to chemical constituents of fine particulate matter(PM2. 5) and mortality in Medicare enrollees in the eastern United States. Environ Health Perspect. 2015:5:467-74.

45. Colditz GA, Frazier AL. Models of breast cancer show that risk is set by events of early life: prevention efforts must shift focus. Cancer Epidemiol Biomarkers Prev. 1995;4:567-71.

46. Colditz GA. Epidemiology and prevention of breast cancer. Cancer Epidemiol Biomarkers Prev. 2005;14:768-72.

47. Fenton SE, Birnbaum LS. Timing of environmental exposures as a critical element in breast cancer risk. J Clin Endocrinol Metab. 2015;100:3245-50.

48. Pike MC, Krailo MD, Henderson BE, Casagrande JT, Hoel DG. "Hormonal" risk factors, "breast tissue age" and the age-incidence of breast cancer. Nature. 1983;303:767-70.

49. Hart JE, Liao X, Hong B, Puett RC, Yanosky JD, Suh H, et al. The association of long-term exposure to PM2.5 on all-cause mortality in the Nurses' Health Study and the impact of measurement-error correction. Environ Health. 2015;14:38.

50. Puett RC, Hart JE, Yanosky JD, Paciorek C, Schwartz J, Suh H, et al. Chronic fine and coarse particulate exposure, mortality, and coronary heart disease in the Nurses' Health Study. Environ Health Perspect. 2009;117:1697-701.

51. Puett RC, Schwartz J, Hart JE, Yanosky JD, Speizer FE, Suh H, et al. Chronic particulate exposure, mortality, and coronary heart disease in the Nurses' Health Study. Am J Epidemiol. 2008;168:1161-8.

52. Zhang Z, Laden F, Forman JP, Hart JE. Long-term exposure to particulate matter and self-reported hypertension: a prospective analysis in the Nurses' Health Study. Environ Health Perspect. 2016;124:1414-20.

53. Pun VC, Hart JE, Kabrhel C, Camargo CA, Baccarelli AA, Laden F. Prospective study of ambient particulate matter exposure and risk of pulmonary embolism in the Nurses' Health Study Cohort. Environ Health Perspect. 2015:123:1265-70

54. Weuve J, Puett RC, Schwartz J, Yanosky JD, Laden F, Grodstein F. Exposure to particulate air pollution and cognitive decline in older women. Arch Intern Med. 2012;172:219-27. 